\title{
Effect and clinical value of coagulation test on adverse reactions of blood transfusion in patients with major bleeding in ectopic pregnancy
}

\author{
FANJIU KONG ${ }^{1}$, YINGBO $\mathrm{LI}^{2}$ and XIAOXIN $\mathrm{LIU}^{3}$ \\ ${ }^{1}$ Department of Blood Transfusion, Zibo First Hospital, Zibo, Shandong 255200; \\ ${ }^{2}$ Department of Blood Transfusion, Weihai Central Hospital, Weihai, Shandong 264400; \\ ${ }^{3}$ Department of Blood Transfusion, Shandong Provincial Qianfoshan Hospital, Jinan, Shandong 250014, P.R. China
}

Received March 21, 2018; Accepted September 11, 2018

DOI: 10.3892/etm.2018.6804

\begin{abstract}
Influence and clinical value of coagulation test on adverse reactions of blood transfusion in patients with major bleeding of ectopic pregnancy were analyzed. Six hundred and twenty-seven cases of ectopic pregnancy admitted to Zibo First Hospital from July 2014 to March 2017 were retrospectively analyzed. The 369 patients who had adverse reactions after blood transfusion were selected as the experimental group. Another 258 patients without adverse reaction after blood transfusion were selected as the control group. Blood samples were collected $8 \mathrm{~h}$ before and after blood transfusion in both groups, and blood test was performed including blood count (RBC), white blood cell count (WBC), platelet count (PLT), HB, hematocrit (HCT), as well as indicators of coagulation, including thrombin time (TT), prothrombin time (PT), activated partial thromboplastin time (APTT) and fibrinogen (FIB). There was no significant difference between the two groups in blood routine and blood coagulation test $(\mathrm{P}>0.05)$. After transfusion, the RBC, WBC, PLT, HB and HCT in the experimental group were significantly lower than those in the control group $(\mathrm{P}<0.05)$. TT, PT and APTT were higher than those in the control group $(\mathrm{P}<0.05)$, while FIB was significantly lower than that in the control group $(\mathrm{P}<0.001)$. The coagulation in the experimental group after blood transfusion was significantly worse than that in the control group. Coagulation test can be used as a marker of adverse reactions after transfusion in patients with massive bleeding in pregnancy, providing reference and guidance for clinical diagnosis and treatment.
\end{abstract}

Correspondence to: Dr Xiaoxin Liu, Department of Blood Transfusion, Shandong Provincial Qianfoshan Hospital, 16766 Jingshi Road, Jinan, Shandong 250014, P.R. China

E-mail: fxn2wa@163.com

Key words: coagulation, ectopic pregnancy, bleeding, transfusion therapy

\section{Introduction}

Approximately $28 \%$ of pregnant women experience ectopic pregnancy during childbirth (1), of which intra-abdominal hemorrhage is the most common complication of ectopic pregnancy (2). According to the statistics report by Riaz et al (3), the occurrence of massive bleeding in patients with ectopic pregnancy was as high as $69.5 \%$. Abdominal bleeding will lead to difficult births, fetal death and suffocation, and serious bleeding will even threaten life (4). For patients with massive bleeding in pregnancy, blood transfusions are given in clinical practice, and generally can have a good rescue effect on patients with acute ischemia (5). However, patients with massive bleeding are prone to adverse reactions, and Magee et al (6) reported that approximately $70 \%$ of patients with pregnancy-induced bleeding occurred varying degrees of adverse reactions. Therefore, how to effectively avoid and reduce adverse reactions in patients has become an important clinical topic. In recent years, multiple studies (7-9) have demonstrated that monitoring blood coagulation is of great clinical significance for patients undergoing transfusion and can effectively determine the patient's blood flow. For patients with massive bleeding during pregnancy undergoing blood transfusion therapy, whether detecting the coagulation function also has high value has not been studied. Therefore, this retrospective comparative analysis of adverse reactions and no adverse reactions in patients with massive bleeding in pregnancy before and after blood transfusion was carried out in order to provide effective and reliable reference for future clinical response to such patients.

\section{Patients and methods}

Patient information. A total of 627 pregnant women admitted to Zibo First Hospital (Zibo, China) from July 2014 to March 2017 were retrospectively analyzed. Patients were aged 22-35 years, mean age 27.34 \pm 5.43 years. In the selected patients bleeding during pregnancy with transfusion in Zibo First Hospital, 369 patients had adverse reactions after blood transfusions (hypotension, tachycardia, urticaria and postoperative infection) and were selected as the experimental group. 
Table I. Blood transfusion standards.

\begin{tabular}{lc}
\hline Blood loss of patients & Blood transfusion content \\
\hline HB $<70 \mathrm{~g} / 1$ & Red blood cell suspension \\
PT & Fresh frozen \\
APTT $>1.5$ times FIB & plasma or cryoprecipitate \\
PLT $<50 \times 10^{9} / 1$ & Apheresis platelets \\
\hline
\end{tabular}

HB, hemoglobin; PT, prothrombin time; APTT, activated partial thromboplastin time; FIB, fibrinogen; PLT, platelet count; PT, clotting time.

Table II. Comparison of clinical data between two groups $(\mathrm{n}, \%)$.

\begin{tabular}{|c|c|c|c|c|}
\hline \multirow[b]{2}{*}{ Items } & \multicolumn{2}{|c|}{ Groups } & \multirow[b]{2}{*}{$\mathrm{t} / \chi^{2}$} & \multirow[b]{2}{*}{ P-value } \\
\hline & $\begin{array}{l}\text { Experimental } \\
\quad(\mathrm{n}=369)\end{array}$ & $\begin{array}{l}\text { Control } \\
(n=258)\end{array}$ & & \\
\hline Age (years) & $26.83 \pm 4.69$ & $26.94 \pm 5.09$ & 0.28 & 0.780 \\
\hline $\begin{array}{l}\text { Pregnancy time } \\
\text { (weeks) }\end{array}$ & $12.35 \pm 1.82$ & $12.62 \pm 2.04$ & 1.74 & 0.083 \\
\hline Weight (kg) & & & 0.02 & 0.897 \\
\hline$<60$ & $134(36.31)$ & $95(36.82)$ & & \\
\hline$\geq 60$ & $235(63.69)$ & $163(63.18)$ & & \\
\hline Smoking habits & & & 0.08 & 0.775 \\
\hline Yes & $25(6.78)$ & $16(6.20)$ & & \\
\hline No & $344(93.22)$ & $242(93.80)$ & & \\
\hline Drinking habits & & & 0.27 & 0.604 \\
\hline Yes & $39(10.57)$ & $24(9.30)$ & & \\
\hline No & $330(89.43)$ & $234(90.70)$ & & \\
\hline Exercise habits & & & 0.10 & 0.748 \\
\hline Yes & $127(34.42)$ & $92(35.66)$ & & \\
\hline No & $242(65.58)$ & $166(64.34)$ & & \\
\hline $\begin{array}{l}\text { Degree of } \\
\text { education }\end{array}$ & & & 0.15 & 0.696 \\
\hline$<$ High school & $126(34.15)$ & $92(35.66)$ & & \\
\hline$\geq$ High school & $243(65.85)$ & $166(64.34)$ & & \\
\hline
\end{tabular}

Another 258 patients without adverse reactions were selected as the control group.

Inclusion and exclusion criteria. Inclusion criteria were: All pregnant patients admitted for childbirth in Zibo First Hospital; have complete case details, aged between 22-35 years. Exclusion criteria were: Suffering from other blood diseases, suffering from other immune diseases, suffering from other heart and brain and other organ diseases, physical disability, surgical tolerance of patients, preoperative chemotherapy. The study was approved by the Ethics Committee of Zibo First Hospital. Patients who participated in this research had complete clinical data. Signed informed consents were obtained from the patients or the guardians.
Table III. Blood test results of two groups before transfusion.

\begin{tabular}{lcccr}
\hline \multicolumn{5}{c}{ Groups } \\
\cline { 2 - 4 } Items & $\begin{array}{c}\text { Experimental } \\
(\mathrm{n}=369)\end{array}$ & $\begin{array}{c}\text { Control } \\
(\mathrm{n}=258)\end{array}$ & $\mathrm{t}$ & P-value \\
\hline RBC $\left(\times 10^{12} / 1\right)$ & $2.63 \pm 0.57$ & $2.65 \pm 0.55$ & 0.44 & 0.661 \\
WBC $\left(\times 10^{9} / 1\right)$ & $4.86 \pm 1.37$ & $5.01 \pm 1.53$ & 1.29 & 0.199 \\
PLT $\left(\times 10^{9} / 1\right)$ & $48.60 \pm 6.52$ & $49.34 \pm 7.06$ & 1.35 & 0.177 \\
HB $(\mathrm{g} / \mathrm{l})$ & $45.36 \pm 12.26$ & $44.67 \pm 13.07$ & 0.67 & 0.500 \\
HCT & $0.26 \pm 0.06$ & $0.26 \pm 0.03$ & 0.0 & $>0.999$ \\
\hline
\end{tabular}

RBC, red blood cell count; WBC, white blood cell count; PLT, platelet count; HB, hemoglobin; HCT, hematocrit.

Methods. Criteria for determining massive bleeding were with reference to 2013 guidelines for the diagnosis of ectopic pregnancy (10): Blood loss $>1,000 \mathrm{ml}$. Patients with massive bleeding in pregnancy was treated with strict reference to the guidelines for the treatment for blood transfusions in 2013 (11), and the blood transfusion standards are shown in Table I. After each infusion of 4-6 U red blood cells or 400-600 ml of blood, the patient's coagulation function was tested, so that coagulation of patients was maintained at normal conditions, and the patient was given intravenous injection of $1 \mathrm{gr}$ calcium gluconate. From the two groups of patients $4 \mathrm{ml}$ venous blood was drawn $8 \mathrm{~h}$ before and after blood transfusion, one sample for blood tests (using the Beckman DHS hematology analyzer, Beckman Coulter, Inc., Brea, CA, USA) and one sample for coagulation tests after centrifugation at 3,250 x g for $5 \mathrm{~min}$ at $4^{\circ} \mathrm{C}$.

Observation indicator. Blood routine observation index: Red blood cell count (RBC), white blood cell count (WBC), platelet count (PLT), HB, hematocrit (HCT). Coagulation function indicators: Thrombin time (TT), prothrombin time (PT), activated partial thromboplastin time (APTT), fibrinogen (FIB).

Statistical analysis. SPSS 22.0 statistical software (IBM Corp., Armonk, NY, USA) was used to analyze and process the data. The enumeration data are expressed as rate. Chi-square test was used to compare between groups. Measurement data are expressed as mean \pm standard deviation, and t-test was used to compare between groups. Paired t-test was used for comparison between before and after treatment. $\mathrm{P}<0.05$ was considered to indicate a statistically significant difference.

\section{Results}

Basic information of the patients. The clinical data of two groups of patients were compared. There was no significant difference between the two groups in age, pregnancy time, body weight, smoking, drinking, exercise habits and education level $(\mathrm{P}>0.05)$ (Table II).

Blood test results before and after blood transfusion. There was no significant difference in RBC, WBC, PLT, HB, HCT 
Table IV. Blood test results of two groups after transfusion.

\begin{tabular}{lccrcc}
\hline & \multicolumn{2}{c}{ Groups } & & \\
\cline { 2 - 3 } Items & $\begin{array}{c}\text { Experimental } \\
(\mathrm{n}=369)\end{array}$ & $\begin{array}{c}\text { Control } \\
(\mathrm{n}=258)\end{array}$ & $\mathrm{t}$ & P-value \\
\hline $\mathrm{RBC}\left(\times 10^{12} / \mathrm{l}\right)$ & $3.74 \pm 0.69$ & $4.84 \pm 0.51$ & 21.78 & $<0.001$ \\
$\mathrm{WBC}\left(\mathrm{x} 10^{9} / \mathrm{l}\right)$ & $6.56 \pm 2.08$ & $7.64 \pm 1.89$ & 6.64 & $<0.001$ \\
$\mathrm{PLT}\left(\mathrm{x} 10^{9} / 1\right)$ & $102.23 \pm 10.62$ & $135.22 \pm 14.53$ & 32.84 & $<0.001$ \\
HB $(\mathrm{g} / \mathrm{l})$ & $78.63 \pm 7.05$ & $91.36 \pm 9.56$ & 19.19 & $<0.001$ \\
HCT & $0.34 \pm 0.08$ & $0.45 \pm 0.06$ & 18.71 & $<0.001$ \\
\hline
\end{tabular}

RBC, red blood cell count; WBC, white blood cell count; PLT, platelet count; HB, hemoglobin; HCT, hematocrit.

Table V. Coagulation tests results in two groups before blood transfusion.

\begin{tabular}{lrrrrr}
\hline & \multicolumn{2}{c}{ Groups } & & \\
\cline { 2 - 3 } Items & $\begin{array}{c}\text { Experimental } \\
(\mathrm{n}=369)\end{array}$ & \multicolumn{1}{c}{$\begin{array}{c}\text { Control } \\
(\mathrm{n}=258)\end{array}$} & $\mathrm{t}$ & P-value \\
\hline TT $(\mathrm{sec})$ & $20.53 \pm 3.52$ & $20.27 \pm 3.08$ & 0.96 & 0.339 \\
PT $(\mathrm{sec})$ & $16.49 \pm 2.36$ & $16.82 \pm 2.51$ & 1.68 & 0.094 \\
APTT $(\mathrm{sec})$ & $36.59 \pm 4.35$ & $35.98 \pm 5.04$ & 1.62 & 0.106 \\
FIB $(\mathrm{g} / \mathrm{l})$ & $1.20 \pm 0.25$ & $1.19 \pm 0.18$ & 0.55 & 0.582 \\
\hline
\end{tabular}

TT, thrombin time; PT, prothrombin time; APTT, activated partial thromboplastin time; FIB, fibrinogen.

Table VI. Coagulation tests results in two groups after blood transfusion.

\begin{tabular}{lrrrrr}
\hline & \multicolumn{2}{c}{ Groups } & & \\
\cline { 2 - 3 } Items & $\begin{array}{c}\text { Experimental } \\
(\mathrm{n}=369)\end{array}$ & $\begin{array}{c}\text { Control } \\
(\mathrm{n}=258)\end{array}$ & $\mathrm{t}$ & P-value \\
\hline TT $(\mathrm{sec})$ & $30.26 \pm 1.62$ & $17.65 \pm 1.53$ & 98.12 & $<0.001$ \\
PT $(\mathrm{sec})$ & $20.53 \pm 2.83$ & $13.42 \pm 2.82$ & 31.00 & $<0.001$ \\
APTT $(\mathrm{sec})$ & $42.49 \pm 4.56$ & $28.65 \pm 1.69$ & 46.56 & $<0.001$ \\
FIB $(\mathrm{g} / \mathrm{l})$ & $2.15 \pm 0.62$ & $4.32 \pm 0.82$ & 37.71 & $<0.001$ \\
\hline
\end{tabular}

TT, thrombin time; PT, prothrombin time; APTT, activated partial thromboplastin time; FIB, fibrinogen.

between the blood transfusion group and the control group before the blood transfusion $(\mathrm{P}>0.05)$. The $\mathrm{RBC}$ in the experimental group after transfusion was $3.74 \pm 0.69 \times 10^{12} / 1$, which was significantly lower than that in the control group $4.84 \pm 0.51 \times 10^{12} / 1(\mathrm{P}<0.001)$. The $\mathrm{WBC}$ in the experimental group was $6.56 \pm 2.08 \times 10^{9} / 1$, which was significantly lower than that in the control group $7.64 \pm 1.89 \times 10^{9} / 1(\mathrm{P}<0.001)$. The levels of PLT, HB and HCT were $102.23 \pm 10.62 \times 10^{9} / 1,78.63 \pm 7.05 \mathrm{~g} / 1$ and $0.34 \pm 0.08$ respectively, which were also lower than those

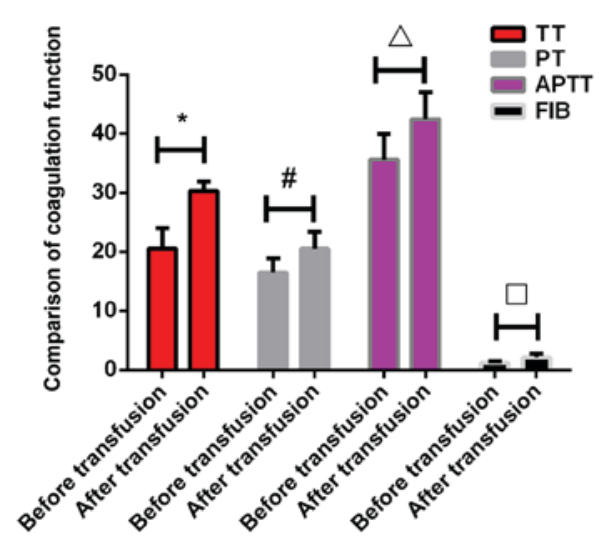

Figure 1. Comparison of coagulation function before and after transfusion in the experimental group. ${ }^{*} \mathrm{P}<0.05$, TT before and after transfusion, and blood transfusion was significantly lower before transfusion in comparison to after transfusion. "P<0.05, PT before and after transfusion, and transfusion was significantly lower before transfusion than after transfusion. ${ }^{\triangle} \mathrm{P}<0.05$, APTT before and after transfusion. Compared with before transfusion, APTT was significantly higher than after transfusion. ${ }^{\square} \mathrm{P}<0.05$, FIB before and after transfusion, and FIB was significantly lower before transfusion than after transfusion.

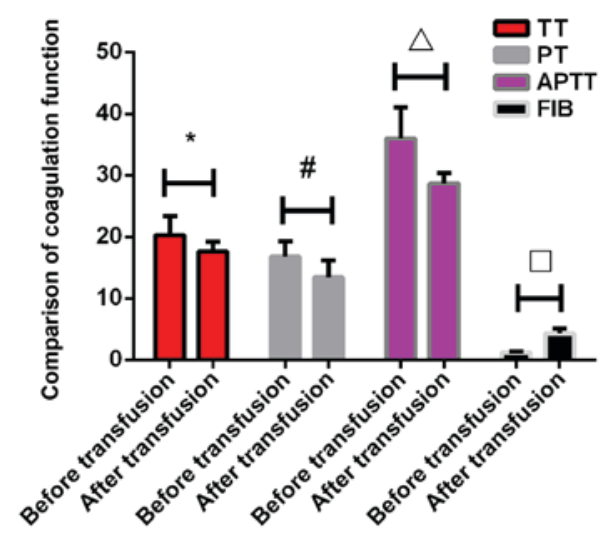

Figure 2. Comparison of coagulation function before and after transfusion in the control group. ${ }^{*} \mathrm{P}<0.05$, TT before and after transfusion, and blood transfusion was significantly higher before transfusion than after transfusion. ${ }^{\text {"}} \mathrm{P}<0.05$, PT before and after transfusion, and transfusion was significantly higher before transfusion than after transfusion. ${ }^{\wedge} \mathrm{P}<0.05$, APTT before and after transfusion, and APTT was significantly higher before transfusion than after transfusion. ${ }^{\square} \mathrm{P}<0.05$, FIB before and after transfusion, and FIB was significantly lower before transfusion than after transfusion.

in the control group $135.22 \pm 14.53 \times 10^{9} / 1,91.36 \pm 9.56 \mathrm{~g} / 1$ and $0.45 \pm 0.06$ respectively $(\mathrm{P}<0.001)$ (Tables III and IV).

Blood coagulation test results before and after transfusion. There were no significant differences in TT, PT, APTT and FIB before transfusion between the two groups $(\mathrm{P}>0.05)$. The TT in the experimental group after transfusion was $30.26 \pm 1.6 \mathrm{sec}$, which was significantly higher than that in control group $17.65 \pm 1.53 \mathrm{sec}(\mathrm{P}<0.001)$. The $\mathrm{PT}$ in the experimental group after transfusion was $20.53 \pm 2.83 \mathrm{sec}$, which was also significantly higher than that in the control group $13.42 \pm 2.82 \mathrm{sec}(\mathrm{P}<0.001)$. The APTT in the experimental group after transfusion was $42.49 \pm 4.56 \mathrm{sec}$, which was significantly higher than that in the control group $28.65 \pm 1.69 \mathrm{sec}$ $(\mathrm{P}<0.001)$. The FIB in the experimental group after transfusion was $2.15 \pm 0.62 \mathrm{~g} / \mathrm{l}$, which was significantly lower than that 
in the control group 4.32 $\pm 0.82 \mathrm{~g} / 1(\mathrm{P}<0.005)$. All indexes of coagulation function in the experimental group were significantly increased after transfusion compared with those before transfusion $(\mathrm{P}<0.05)$. However, the levels of TT, PT and APTT in the control group were significantly lower than those before the transfusion $(\mathrm{P}<0.05)$, while the levels of FIB in the control group were significantly higher than those before transfusion $(\mathrm{P}<0.05)$ (Tables V and VI; Figs. 1 and 2).

\section{Discussion}

Massive bleeding in ectopic pregnancy patients leads to critical condition, lack of blood circulation, decreased red blood cell oxygen carrying capacity, decreased blood perfusion which causes a serious threat to the patients and the fetuses $(12,13)$. In clinical practice, these patients are mainly treated with blood transfusion for emergency rescue, and the purpose of which is to supplement the patient's blood volume and blood coagulation factors, and to improve the patient's hypoxia-induced necrosis caused by ischemia $(14,15)$. Transfusion therapy can not only strive for more treatment time, but also provide more effective protection for the fetus of patients (16). However, patients occur with different degrees of adverse reactions after massive bleeding, and the adverse reactions not only may make the disease become more complex, severe adverse reactions will directly result in premature birth and stillbirth $(17,18)$. Our study found that the detection of coagulation in pregnant patients can be used as an indicator of adverse reactions in patients and can be implemented in the clinic.

The results of this study showed that coagulation disorders were common in patients with massive bleeding during the course of transfusion therapy. The blood parameters before and after transfusion were improved in both groups, but the improvement in the control group was significantly better than that in the experimental group, suggesting that adverse reactions of bleeding can affect the recovery of blood condition in pregnant patients. After transfusion, the indexes of coagulation function in the experimental group were significantly increased, while the TT, PT and APTT in the control group showed a downward trend and the FIB increased. Adverse reactions affect the patient's coagulation function, adverse reactions in the experimental group of patients resulting in poor effects of transfusion therapy. For patients with ectopic pregnancy, due to massive bleeding caused by rupture of fallopian tube, and pregnancy also speeds up the rate of blood coagulation, causing diffuse blood clotting, it will not only lead to coagulation disorders in patients, but also may lead to rupture of fetal membranes in patients and cause injury to the fetus (19).

By detecting the difference of coagulation function before and after transfusion, the improvement of coagulation function in the experimental group was significantly worse than that in the control group. Although the FIB in the experimental group also increased significantly compared with that before treatment, the increase was not as good as that in the control group. The reason for this is that FIB is a glycoprotein involved in the coagulation of the patient. When the patient's ability to synthesize protein is weakened, the FIB will show a downward trend $(20,21)$. Therefore, for patients with adverse reactions, their protein synthesis ability has been suppressed, resulting in non-significant improvement of FIB protein after transfusion. However, the increase of PT, TT and APTT showed that the decrease of coagulation function in the experimental group aggravated the possibility of bleeding in patients.

In this study, due to limited conditions, there are still deficiencies, such as the study population, relatively simple testing instruments, and we will be performing follow-up survey for a longer period and continuing to improve our experiment in the future, in order to achieve the best experimental results.

In conclusion, coagulation test can be used as an indicator of adverse reactions in patients with massive bleeding in pregnancy after transcortical treatment, providing reference and guidance for clinical diagnosis and treatment.

\section{Acknowledgements}

Not applicable.

\section{Funding}

No funding was received.

\section{Availability of data and materials}

The datasets used and/or analyzed during the present study are available from the corresponding author on reasonable request.

\section{Authors' contributions}

FK designed the study, wrote the manuscript and treated patients. YL was responsible for blood routine observation index. XL collected and analyzed basic information on patients. All authors read and approved the final manuscript.

\section{Ethics approval and consent to participate}

The study was approved by the Ethics Committee of Zibo First Hospital (Zibo, China). Patients who participated in this research had complete clinical data. Signed informed consents were obtained from the patients or the guardians.

\section{Patient consent for publication}

Not applicable.

\section{Competing interests}

The authors declare that they have no competing interests.

\section{References}

1. Perkins KM, Boulet SL, Kissin DM and Jamieson DJ; National ART Surveillance (NASS) Group: Risk of ectopic pregnancy associated with assisted reproductive technology in the United States, 2001-2011. Obstet Gynecol 125: 70-78, 2015.

2. Fang C,Huang R, Wei LN and Jia L: Frozen-thawed day 5 blastocyst transfer is associated with a lower risk of ectopic pregnancy than day 3 transfer and fresh transfer. Fertil Steril 103: 655-661. e3, 2015.

3. Riaz RM, Williams TR, Craig BM and Myers DT: Cesarean scar ectopic pregnancy: Imaging features, current treatment options, and clinical outcomes. Abdom Imaging 40: 2589-2599, 2015. 
4. Taran FA, Kagan KO, Hubner M, Hoopmann M, Wallwiener D and Brucker S: The diagnosis and treatment of ectopic pregnancy. Dtsch Arztebl Int 112: 693-703, 2015.

5. Kelly RJ, Höchsmann B, Szer J, Kulasekararaj A, de Guibert S, Röth A, Weitz IC, Armstrong E, Risitano AM, Patriquin CJ, et al: Eculizumab in pregnant patients with paroxysmal nocturnal hemoglobinuria. N Engl J Med 373: 1032-1039, 2015.

6. Magee LA, von Dadelszen P, Rey E, Ross S, Asztalos E, Murphy KE, Menzies J, Sanchez J, Singer J, Gafni A, et al: Less-tight versus tight control of hypertension in pregnancy. N Engl J Med 372: 407-417, 2015.

7. Wafaisade A, Wyen H, Mutschler M, Lendemans S, Bouillon B, Flohe S, Paffrath T, Maegele M, Tjardes T and Probst C; Sektion NIS der DGU: Current practice in coagulation and transfusion therapy in multiple trauma patients: A German nation-wide online survey. Unfallchirurg 118: 1033-1040, 2015 (In German).

8. Nystrup KB, Stensballe J, Bøttger M, Johansson PI and Ostrowski SR: Transfusion therapy in paediatric trauma patients: A review of the literature. Scand J Trauma Resusc Emerg Med 23: 21, 2015.

9. Karkouti K, McCluskey SA, Callum J, Freedman J, Selby R, Timoumi T, Roy D and Rao V: Evaluation of a novel transfusion algorithm employing point-of-care coagulation assays in cardiac surgery: A retrospective cohort study with interrupted time-series analysis. Anesthesiology 122: 560-570, 2015.

10. Alkatout I, Honemeyer U, Strauss A, Tinelli A, Malvasi A Jonat W, Mettler L and Schollmeyer T: Clinical diagnosis and treatment of ectopic pregnancy. Obstet Gynecol Surv 68: 571-581, 2013.

11. Heal JM and Blumberg N: Optimizing platelet transfusion therapy. Blood Rev 18: 149-165, 2004.

12. Detterich JA, Kato RM, Rabai M, Meiselman HJ, Coates TD and Wood JC: Chronic transfusion therapy improves but does not normalize systemic and pulmonary vasculopathy in sickle cell disease. Blood 126: 703-710, 2015.
13. Beverung LM, Strouse JJ, Hulbert ML, Neville K, Liem RI, Inusa B, Fuh B, King A, Meier ER, Casella J, et al; SIT trial investigators: Health-related quality of life in children with sickle cell anemia: Impact of blood transfusion therapy. Am J Hematol 90: 139-143, 2015.

14. Gutfraind A and Meyers LA: Evaluating large-scale blood transfusion therapy for the current Ebola epidemic in Liberia. J Infect Dis 211: 1262-1267, 2015.

15. Marfin AA and Price TH: Granulocyte transfusion therapy. J Intensive Care Med 30: 79-88, 2015.

16. Chou ST and Fasano RM: Management of patients with sickle cell disease using transfusion therapy: Guidelines and complications. Hematol Oncol Clin North Am 30: 591-608, 2016.

17. Taher AT, Radwan A and Viprakasit V: When to consider transfusion therapy for patients with non-transfusion-dependent thalassaemia. Vox Sang 108: 1-10, 2015.

18. Colebunders RL and Cannon RO: Large-scale convalescent blood and plasma transfusion therapy for Ebola virus disease. J Infect Dis 211: 1208-1210, 2015.

19. Berry J, Davey M, Hon MS and Behrens R: A 5-year experience of the changing management of ectopic pregnancy. J Obstet Gynaecol 36: 631-634, 2016.

20. Liu CH, Gong P and Yang J: Relationship between circulating tumor cells and coagulation factors in primary lung cancer patients. Zhonghua Zhong Liu Za Zhi 38: 368-371, 2016 (In Chinese).

21. Onelöv L, Gustafsson E, Grönlund E, Andersson H, Hellberg G, Järnberg I, Schurow S, Söderblom L and Antovic JP: Autoverification of routine coagulation assays in a multi-center laboratory. Scand J Clin Lab Invest 76: 500-502, 2016.

This work is licensed under a Creative Commons

Attribution-NonCommercial-NoDerivatives 4.0 International (CC BY-NC-ND 4.0) License. 